\title{
COMPOSITION OF NORMAL AND MOTTLED CITRUS LEAVES
}

W. P. KELLEY AND A. B. CUMMINS

Reprinted from JOURNAL OF AGRICULTURAL RESEARCH

Vol. XX, No. 3 : : : : Washington, D. C., November 1, 1920

PUBLISHED BY AOTHORITY OF THE SECRETARY OF AGRICULTURE, WITH THE COOPERATION OF THE ASSOCLATION OF LAND-GRANT COLLEGES 


\section{COMPOSITION OF NORMAL AND MOTTLED CITRUS LEAVES 1}

By W. P. Kelley and A. B. Cummins, Citrus Experiment Station, College of Agriculture, University of California

\section{INTRODUCTION}

Knowledge concerning the composition of a plant is essential to an understanding of its growth. The amounts and proportions of the different constituents absorbed from the soil or other nutrient medium, as revealed by accurate analysis of the several parts of plants, undoubtedly give some indication concerning their nutritional requirements. If determined progressively, such data may contribute to a clearer understanding of fundamental physiological processes of growth.

The interpretation of plant analyses, so far as growth processes and requirements are concerned, demands great caution, however. Many plants undoubtedly have the power of adapting themselves to a wide range of soil variations; and the composition of the plant, owing to selective absorption, commonly bears little direct relation to the composition of the nutrient solution. It is well known that the concentration of a given constituent in the nutrient solution may be varied considerably without producing any material change in the composition of the plant.

The effect of an excess or deficiency of one ion on the absorption of other ions, and especially the effects of nonessential salts on the absorption of essential ions, have not been sufficiently studied. Despite the many investigations during recent years on antagonism, comparatively few analyses have been made showing the effects on absorption. Likewise, investigations on the so-called nutritional or physiological diseases have not dealt with absorption specifically, except to a very limited extent.

Previous studies on the rate of absorption of nutrients have been conducted mainly with annual plants, chiefly cereals, very limited study having been devoted to trees. There is much need for accurate data on the several phases of absorption as related to the growth of fruit trees.

1 Paper No. 67. University of California, Graduate School of Tropical Agriculture and Citrus Experiment Station, Riverside, Calif.

Journal of Agricultural Research,

Washington, D. C.

Vol. XX, No. 3

vh

Nov. $x, 1920$

Key No. Calif.-24 
In connection with investigations on the nutrition of different species of citrus trees, especially as related to that condition known as mottleleaf, we have determined the composition of different parts of the tree, such, for example, as the roots, old wood, young wood, leaves, leaf sap, and fruit. This work has extended over a period of several years, and further study is contemplated. Some of the results already obtained have proved to be of special interest. The present paper will be devoted mainly to a discussion of the composition of the leaves.

It is not necessary to review the many published analyses of citrus fruits. Most of the publications on this subject have dealt mainly with the organic constituents and total ash, with an occasional analysis of the ash. Comparatively few analyses have been published showing the composition of portions of citrus trees other than the fruit.

The earliest investigation we have been able to find, and perhaps the best known, is that of Rowney and How ( 15$)^{1}$, published in 1848 . Analyses were reported of the roots, stems, leaves, and fruit of orange trees, Citrus aurantium, grown on the island of St. Michael. The variety was presumably that now known as St. Michael. ${ }^{2}$ The analyses were expressed as percentages of the carbon-dioxid-free ash. The results were similar to our analyses of California orange trees, when calculated to the same basis.

In I89I Oliveri and Guerrieri ( 13 ) published an extended study on the composition of the wood, leaves, and different portions of the fruit of the orange, Citrus aurantium Riss; ${ }^{2}$ Mandarin, C. nobilis var. deliciosa, Swingle; and lemon, C. limonia Osbeck, grown in Palermo, Italy. This investigation, extending over a period of three years, is the most complete study yet published on the composition of different parts of citrus trees. They recorded the number and weights of fruits produced by different classes of trees and the number and weights of leaves and the weights of wood pruned from the trees during a period of three years, representative samples of which were analyzed. Some of their analyses also agree reasonably closely with our data.

In I9or Aliño ( $I$ ) determined the phosphoric acid, potash, and nitrogen content of orange wood, leaves, and fruit; and in Igog Muller (I2) published complete analyses of seedling orange leaves from healthy and diseased trees grown in South Africa.

In rgro Blair (2) analyzed orange leaves and stems grown in Florida. His samples represented the new growth taken in October from certain plots of a fertilizer experiment. In I9I7 Jensen (7) published a paper on the compesition of normal and mottled orange, lemon, and grape-

1 Reference is made by number (italic) to "Literature cited," p. r90-r 9 r.

2 In this case, the sweet orange, Citrus sinensis Osbeck, is doubtless the species studied. W. T. Swingle's revision of citrus nomenclature, as given in the "American Standard Cyclopedia of Horticulture," is followed in this paper. 
fruit (Citrus grandis Osbeck) leaves grown in California. Further reference will be made to this paper later.

As is well known, the composition of annual herbaceous plants depends on their age. It has been shown that the ash content and the proportions of the individual constituents absorbed from the soil change as growth proceeds. Of the changes in perennials much less is known. It seems reasonable to suppose, however, that the growth processes are similar. The periodically developing new shoots may be likened to the portion of annual plants growing above ground.

New shoots appear on citrus trees several times each year. The tree, being evergreen, bears leaves at all seasons. Consequently, the foliage is composed of leaves of different ages. A given leaf ordinarily remains on the tree for a period of from two to three or more years.

\section{SELECTION OF SAMPLES}

Special care has been taken to secure representative samples of leaves of known age. Familiarity with the appearance of developing citrus leaves proved to be a material aid in selecting the samples. A considerable portion of the samples were obtained from trees growing near the laboratory where daily observations were made. The leaves of the Washington Navel and Valencia orange, the Eureka lemon, and the Marsh seedless grapefruit have been analyzed. Each sample was composed of several hundred leaves, collected from six or more adjacent trees, all of which were reasonably uniform in appearance and the culture and fertilization of which had been the same. The trees were ro or more years of age. The entire leaf, including the petiole, was analyzed as a unit.

The samples were picked from the trees, placed in tight bags and immediately taken to the laboratory and weighed. In most cases this procedure did not require more than 30 minutes. In order to remove dust and other adhering foreign material, the leaves were thoroughly cleaned by wiping each leaf with a moist cloth, but washing with water was necessary with a few samples heavily coated with dust or showing evidences of residues from previous spraying. Early in this work it was found that the samples from which the dust had not been completely removed contained abnormally high percentages of silica, alumina, iron, and inorganic materials not soluble in dilute hydrochloric acid.

\section{METHODS OF ANALYSIS}

The samples were dried at $105^{\circ} \mathrm{C}$. for 24 hours, and the loss in weight was calculated as moisture. The dry samples were ground to a powder in a small hand mill, were thoroughly mixed, and were then stored in tightly stoppered bottles for analysis.

Total nitrogen was determined by the official Kjeldahl method, modified to include nitrates. Total sulphur was determined by the sodium-peroxid 
fusion method. The fusions were made over alcohol flames, and the sulphate was precipitated as barium sulphate, usually from the solution of the entire mass used in making the fusion. Total phosphorus was determined by treating I to $2 \mathrm{gm}$. of the dry material with a solution of magnesium nitrate, evaporating to dryness, igniting, and proceeding in the usual manner. Chlorin was determined in a special portion of the ash made by igniting at a low heat 5 to $10 \mathrm{gm}$. of the dry material, dissolving the residue in dilute nitric acid, and proceeding with the Volhard volumetric method. In some cases chlorin was also determined by performing the incineration in the presence of an excess of sodium carbonate in order to avoid the possible loss of chlorin, but the results of the two methods were similar.

For the determination of total ash, Io to $20 \mathrm{gm}$. of the dry samples were incinerated in porcelain dishes over Bunsen burners. The material charred easily and burned quietly upon the application of low heat and was reduced to a gray ash without approaching dull redness. The residue was then allowed to cool, was taken up with hot water, transferred to a filter, and washed thoroughly. The insoluble material with its filter paper was transferred to a platinum dish, dried, pulverized with an agate pestle, and heated to full redness. When the platinum dish cooled, the filtrate from the previous leaching was added and evaporated to dryness. Ten to $20 \mathrm{cc}$. of strong ammonium-carbonate solution were then added, and the treatment was repeated until the ash was completely carbonated, as was indicated by constant weight upon evaporating to dryness and heating gently. The results are recorded as percentages of ash. It should be stated that the ash thus obtained differs from that reported by other investigators in that we are dealing with completely carbonated ash, whereas previous analyses of citrus leaf ash have been calculated to a carbon-dioxid-free basis.

The ash was dissolved in water and dilute hydrochloric acid, and the solution was evaporated to complete dryness on the water bath in order to dehydrate the silica. The amount of uncombined carbon found in the ash was always entirely negligible. The residue was taken up with warm water and dilute hydrochloric acid. The silica was determined by the loss in weight occasioned by treating the incinerated residue with hydrofluoric acid. The material nonvolatile in hydrofluoric acid usually amounted to only O.I to 0.2 per cent of the ash and was neglected in this work. The filtrate from the silica separation was made up to a definite volume, usually $500 \mathrm{cc}$, and the various constituents were determined in aliquots representing from $0.2 \mathrm{gm}$. to $0.4 \mathrm{gm}$. of the ash.

The methods of the Association of Official Agricultural Chemists ${ }^{1}$ were used with slight modifications, as noted. Iron, aluminum, and

${ }^{1}$ WILEY, H. W., ed. OFFICIAL, AND PROVISIONAL, METHODS OF ANALYSIS, ASSOCIATION OF OFFICLAL AGRITURAL CHEmists. As compiled by the committee on revision of methods. U. S. Dept. Agr. Bur. Chem. Bul. 107 (rev.), 272 p., 13 fig., 1908. Reprinted in 1912. 
phosphoric acid were precipitated collectively by adding a weighed excess of ferric chlorid, neutralizing with ammonia, filtering, redissolving in dilute hydrochloric acid, and repeating the process. Iron was precipitated with ammonia from a separate aliquot and determined volumetrically by reduction with zinc and titration with permanganate. This method was occasionally supplemented by the ferrocyanid colorimetric method with fairly satisfactory results. Aluminum was calculated by difference after the phosphoric acid was gravimetrically determined in a separate aliquot. Calcium, magnesium, potassium, and sodium were determined in the filtrate after the ammonia precipitate was removed, and in some cases manganese was determined by bromin oxidation. Sulphate was determined gravimetrically in an aliquot of the original solution. Carbon dioxid was not determined.

\section{COMPOSITION OF NORMAL MATURE ORANGE LEAVES}

A considerable number of analyses have been made of mature orange leaves representing both the Washington Navel and Valencia varieties. Owing to the absence of previous records showing the age of the leaves available for analysis, and in view of the fact that orange leaves, when from 4 to 6 months of age, assume an appearance not unlike that of leaves I, 2, or more years of age, it is highly probable that random samples will always represent mixed ages. ${ }^{1}$ Most of our samples of mature leaves were taken at random, always avoiding immature or abnormal individuals. The samples were gathered at different, seasons of the year and from a considerable number of different sets of trees, some of which were growing in different localities. Typical analyses are submitted in Tables I and II.

It is interesting to note that the composition of the different samples was found to be reasonably uniform despite the fact that their averageages, although they were mature in appearance, probably varied considerably. Other samples not reported above showed a similar composition. The data also afford but little evidence of seasonal variation in composition.

Except in calcium and potassium content, the different samples of the same variety differed almost as widely in composition as the samples of different varieties. The samples from different localities were also similar in composition, although those from Riverside were grown on sandy loam soil, that from Anaheim on light sandy soil, and the one from Whittier on heavy adobe.

It will be noted that the average calcium content of Valencia leaves was found to be somewhat higher than that of Navels, while the reverse is true for potassium.

1Ensign (6) has recently shown that the size of the vein islets of Citrus grandis is directly correlated with the maturity of the leaf. From the most immature to fully matured leaves there is a gradual increase in the size of the vein islets. If further investigation prove that similar relations occur in other species of citrus, a direct means will be afforded by which the age of the leaves can be determined. 


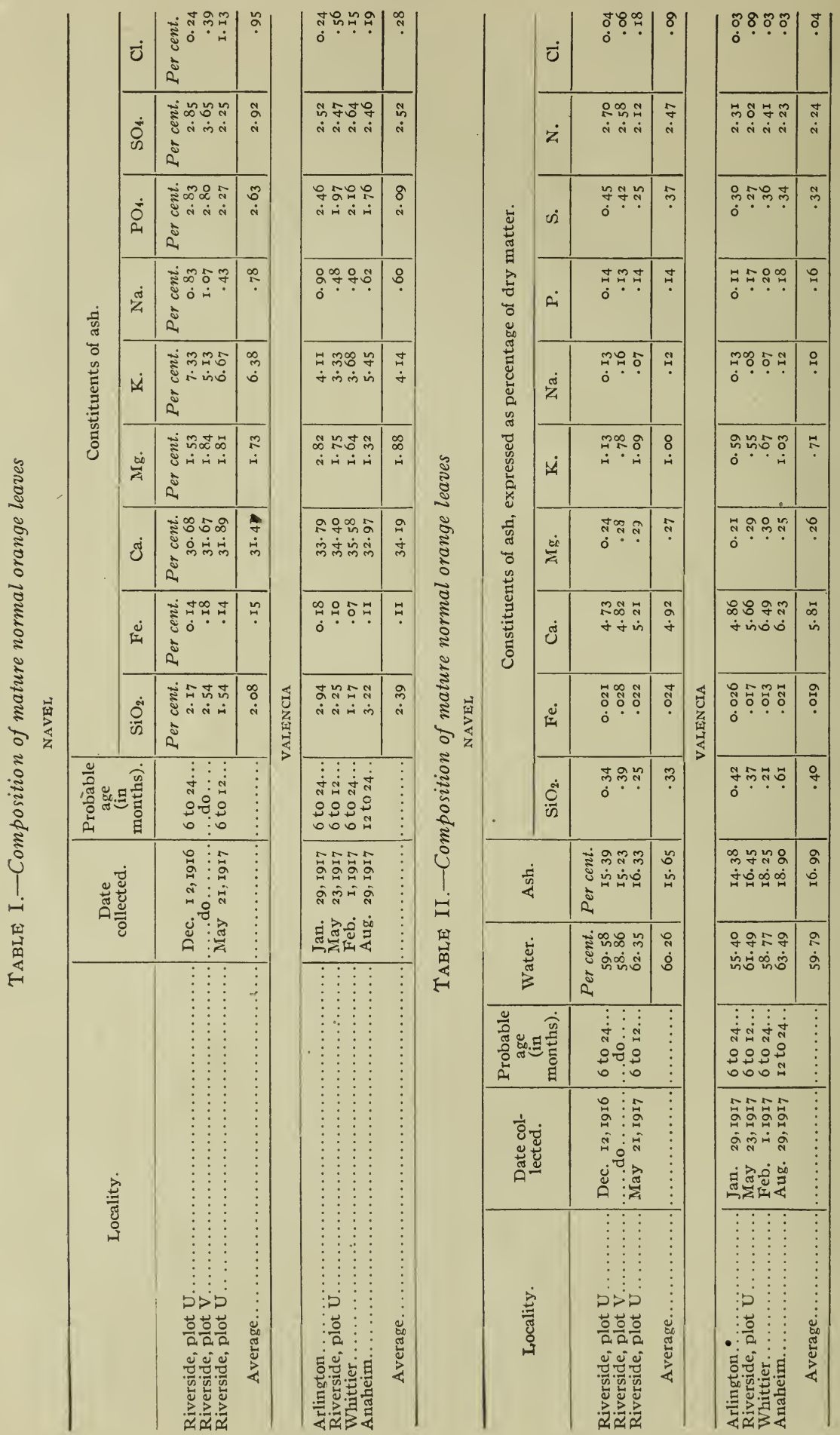


Throughout this work we have determined the aluminum. Qualitative tests usually indicated this element to be present, but the quantity was never more than a few tenths of $x$ per cent of the ash. Frequently the amount was undeterminable. The manganese was also determined in several samples. The amount was found to vary from o.I per cent to 0.2 per cent of the ash.

The size of the leaves as gauged by their average weights was recorded, but there appears to be no consistent difference in composition referable to the size of the leaf. As is well known, the size of apparently normal orange leaves may vary widely. Even on a given tree, the fully mature leaves of certain cycles of growth may be at least twice as large as others.

From the analysis of many other samples in this laboratory it may be said that the composition of mature orange leaves when grown in California is remarkably uniform, provided, however, that the leaves be borne on vigorous trees. On the other hand, the composition of the leaves of improperly nourished and diseased trees may vary widely. If the supply of available nitrate be deficient, the content of nitrogen in the leaves may be considerably below that reported above, but there seems to be some doubt whether the reverse is true.

\section{COMPOSITION OF LEMON AND GRAPEFRUIT LEAVES}

The analysis of mature Eureka lemon and Marsh seedless grapefruit leaves is submitted in Tables III and IV.

Two of the samples of lemon leaves were collected in midwinter and the other on August 29. They were grown on widely different types of soil. The Riverside sample grew on sandy loam, the Whittier sample on heavy adobe, and the Tustin sample on highly calcareous sandy loam soil. The grapefruit leaves were grown on sandy loam.

The composition of the different samples of lemon leaves is fairly uniform, the average being similar to the average composition of Valencia orange leaves. On the other hand, the composition of the grapefruit leaves closely resembles that of Navel orange leaves.

The composition of the leaves of the different varieties and species of citrus has been found to be remarkably uniform from the standpoint of both the ash and the dry matter. A more detailed discussion of the composition will be given below. 


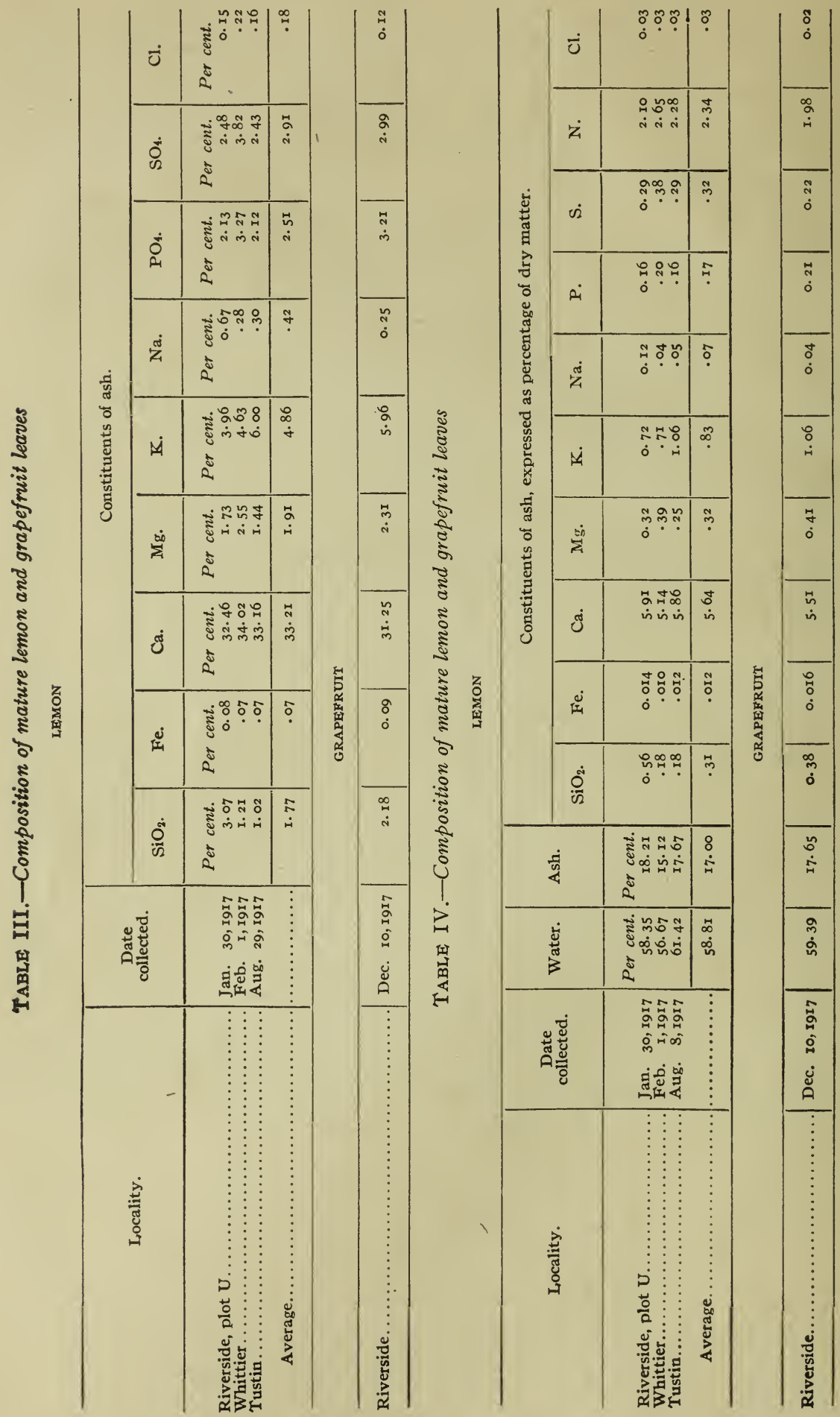


COMPOSITION OF ORANGE LEAVES AT DIFFERENT STAGES OF GROWTH

The results obtained from the analysis of samples of leaves approximately one month of age, gathered on May II, I9I7, were found to be considerably different from previous analyses of mature leaves. Sampics representing the new spring growth and that of the previous year, gathered from the same trees on May 21, I9I 7 , also proved to be widely different in composition. These results, together with the discordance between the analyses previously made in this laboratory and those published by Blair (2) from Florida and by Jensen (7) from California, suggested the desirability of making a study on the composition of orange leaves at different stages of growth.

Samples were collected at four different intervals in the growth cycle. The first represented leaves approximately I week old; the second, those 6 to 8 weeks old; the third, leaves at full maturity, the ages of which ranged from 6 months to approximately 2 years; the fourth, old leaves that were about to be shed, as indicated by their yellowish brown color. Each sample was picked from six normal, vigorously growing trees of plot $\mathrm{V}$ at the Citrus Experiment Station, Riverside, Calif. The samples representing different ages were all taken from the same trees, and those representing the first three periods of growth were gathered on the same day, November 9, 1917. These trees support an abundant foliage; and, as frequently occurs, they at that time bore numerous shoots of varying ages, ranging from a few days to 2 or more years of age, which made it possible to secure samples of widely different ages on a given day. The samples of old leaves were gathered December ro, I917.

The data expressed as percentages of the ash show that notable changes take place in the relations of certain constituents as growth proceeds. Especially prominent among these changes are the decreases in the percentages of phosphate and potassium, on the one hand, and the increases in calcium on the other. For example, the ash of navel leaves at the age of I week was found to contain I 6.83 per cent phosphate $\left(\mathrm{PO}_{4}\right)$, at 6 weeks 7 .Io per cent, at maturity 2.47 per cent, while the ash of old leaves contained only r.32 per cent.

The.changes in the percentages of potassium were quite parallel to those of phosphate. When navel leaves were I week of age, the ash contained 19.87 per cent potassium, when 6 weeks of age, I0.32 per cent, when mature, 5.68 per cent, while the old leaves contained only I.66 per cent.

The percentages of calcium underwent changes quite opposite to those of potassium. With the ash containing 20.72 per cent calcium when the leaves were I week old there was an increase to 28.44 per cent at 6 weeks, to $33.2 \mathrm{I}$ per cent at maturity, and finally to 34.4I per cent in the very old stage. 


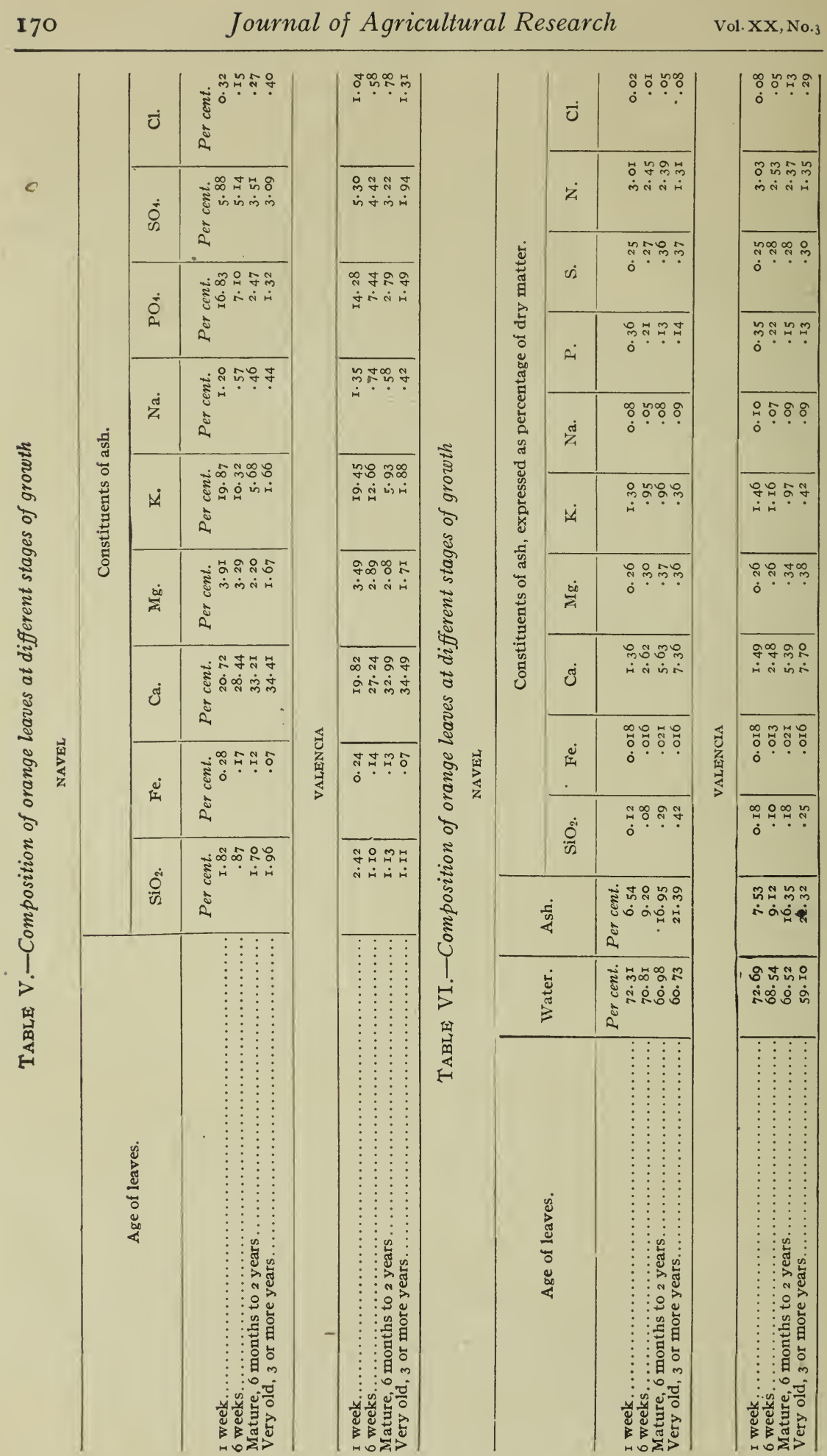


Among the other necessary nutrients, the percentages of iron, magne- sium, and sulphate decreased with age, although to a lesser degree than potassium and phosphate. The ash of the youngest leaves contained approximately twice as much iron as that of the mature leaves, and differences almost as great occurred in the percentages of magnesium and sulphate.

As was anticipated, the changes that take place in Valencia orange leaves are quite similar to those of navel leaves.

The percentages of phosphorus and sulphur refer to the total amounts as determined by the magnesium-nitrate and sodium-peroxid fusion methods, respectively, and are somewhat higher than the corresponding data calculated from the ash analyses. As is well known, organic materials usually lose a portion of their phosphorus and sulphur in the ashing process.

It will be noted that the content of water decreased considerably as growth took place. At I week of age the navel leaves contained 72.3 I per cent water, at 6 weeks 70.8I per cent, at maturity 60.98 per cent, and the very old leaves still contained 60.73 per cent. The content of total ash, on the other hand, increased markedly with age, rising from 6.54 per cent of the dry matter at the age of I week to the very high content of $2 \mathrm{I} .39$ per cent in the old leaves.

The nitrogen decreased from 3.OI per cent at the age of I week to 2.39 per cent at maturity, and finally to I.3 I per cent in the old stage. The percentage of phosphorus decreased still more rapidly during the actively growing period, but later the phosphorus content remained approximately constant. The percentage of potassium also decreased rapidly during the early period of growth but remained almost constant after the second period until the period of senility approached, when a still further decrease took place.

The percentage of iron in the dry matter was found to be reasonably constant at all stages of growth. However, in considering the iron content of these and all other samples reported herein, it is important to bear in mind that the analytical error involved in the determination of small amounts of this element is likely to be relatively great. For this reason small variations in the results are probably not significant. The percentages of sulphur and magnesium each increased somewhat as growth took place.

The constituent of the dry matter of orange leaves that undergoes the greatest percentage change as a result of growth is calcium. At I week of age, the navel leaves contained $1.3^{\circ} 6$ per cent calcium, at 6 weeks 2.62 per cent, at maturity 5.63 per cent, and the very old leaves contained 7.36 per cent.

Of the supposedly unessential constituents, the greatest concentration of sodium was found in the young leaves; but the amount was always small, while the data for silica and chlorin show no consistent variation. 
It is interesting to note that in certain respects the composition of orange leaves changes with growth, somewhat as is the case with the vegetative portion of other plants. With certain cereals a considerable portion of the potassium, magnesium, phosphorus, and nitrogen migrate from the leaves into other parts of the plant as maturity approaches ( 9 , Io). The potassium tends to accumulate in the straw of rice, while the magnesium, phosphorus, and nitrogen are translocated to the grain.

The composition of citrus leaves differs markedly from that of cereals in certain other respects. The ash content of the former increases much more rapidly and reaches a very high point in the old leaves. The calcium content increases very rapidly during the most actively growing period and continues to be deposited in the leaves, although at a somewhat slower rate, almost until the time the leaves fall off.

While it is probable that the composition of normal orange leaves varies to some extent when grown in different parts of the world or on different soils in a given locality, careful study of the analyses of the Florida-grown leaves published by Blair (2) and those reported from Italy by Olivieri and Guerrieri (I 3 ) suggests that these were immature leaves. From Jensen's results (7), it is evident that his samples were not composed of mature leaves. Recognition of the relationships between the age and the composition of orange leaves is especially important in the study of the composition of mottled leaves, as will be pointed out more fully later.

It does not necessarily follow from the preceding discussion that a portion of a given element, potassium, for example, migrates back into other parts of the tree after the leaves reach a certain stage of development. Increase in the size of a leaf, owing to the elaboration of carbonaceous matter, may dilute the nutrients present and, therefore, lower the percentage without there being an actual loss. To establish this point, it is necessary to determine the weights of the constituents present per leaf at different periods. From the average weights of the individual leaves at each period we have calculated the content of the different constituents, expressing the results in grams per $\mathrm{I}, \mathrm{ooo}$ leaves. ('Table VII.)

The old Navel leaves were considerably smaller on the average than either those representing maturity or 6 weeks of age, while the mature Valencia leaves were larger than the old leaves of the same variety. In addition, the leaves of each sample of the Valencia variety were considerably larger than the corresponding Navel leaves.

Despite these irregularities in the size of the leaves, the data show that the content of calcium in a given orange leaf increases very rapidly during the early part of the growth period. In the Navel leaves, approximately a tenfold increase in calcium content took place between the first and the sixth week of age. From the sixth week to maturity a further increase, more than twofold, took place, and finally the calcium content increased still further as the leaves approached the time of normal dropping. 


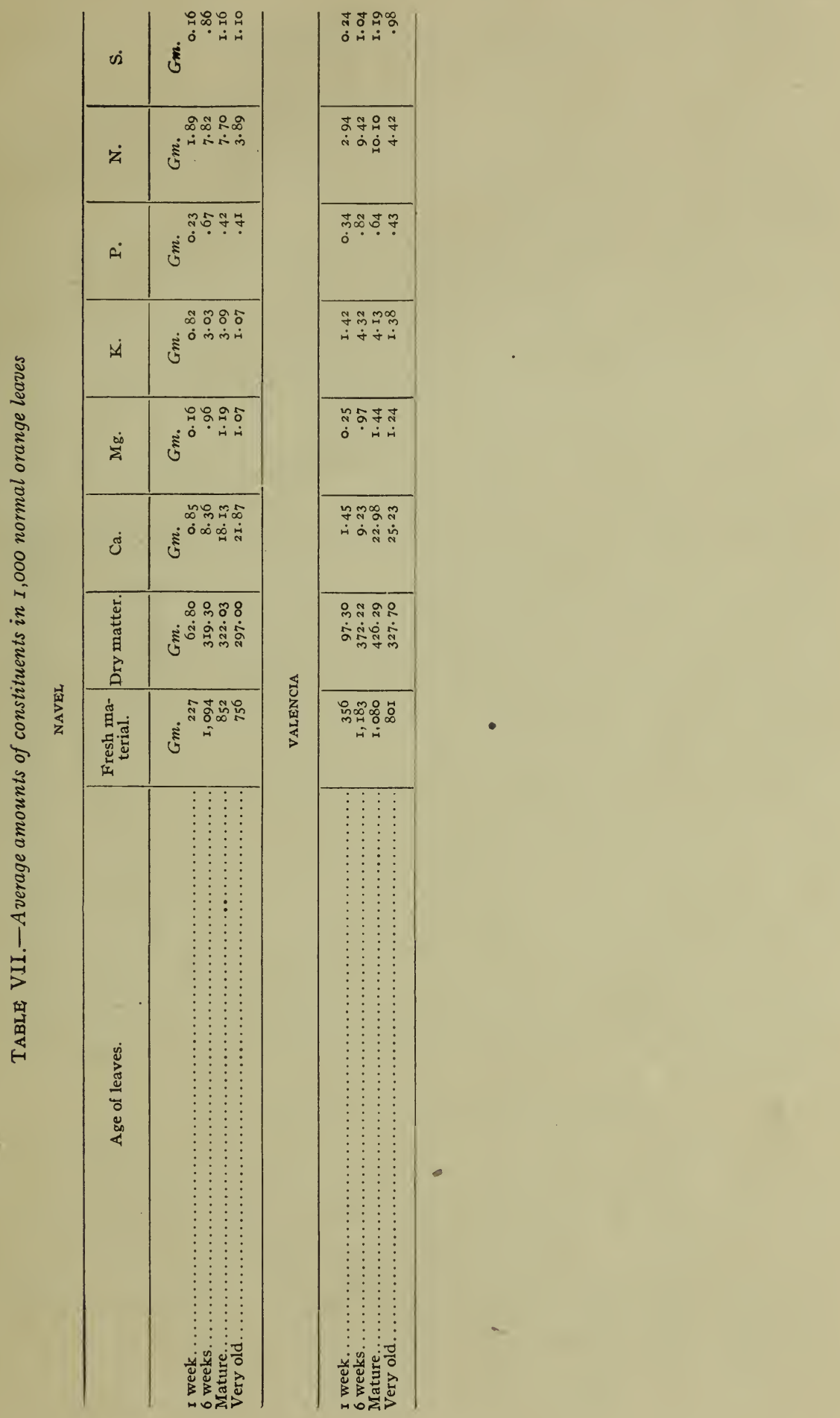


The rates of increase in magnesium and sulphur are also rapid during the early part of the growth period, and each of these constituents continues to accumulate in the leaves up to maturity, but the absolute amounts never become high. Since irregularities occurred in the size of the leaves, it is doubtful whether any important amount of either magnesium or sulphur is translocated to other portions of the tree after maturity has been reached.

The maximum amounts of potassium, phosphorus, and nitrogen were deposited before the leaves were 6 weeks of age. The rates of increase of each were considerably less than that of calcium. The data show that a considerable portion of these elements migrates away from the leaves after certain periods. With potassium and nitrogen the loss takes place after maturity has been reached, while the phosphorus begins to recede even before maturity is attained.

Similar data for iron are omitted because of the magnitude of the analytical error involved in its determination.

Samples representing more frequent intervals in the growth cycle would certainly afford more detailed information regarding absorption. It is possible that the analysis of such samples when plotted might show breaks in the curves not indicated by the existing data. For example, the exact period in the growth cycle when the leaves contained the maximum amount of potassium might be shifted to some extent and other fluctuations might also be found. However, other analyses of immature orange leaves at different seasons of the year show a fairly close agreement with those reported above. On the whole, we are inclined to believe that the main features of the composition of the orange leaf have been determined.

It seems appropriate to emphasize the fact that citrus leaves are extremely calcareous, and much more so than most of the economic plants. As is well known, the ash of some of the legumes contains high percentages of calcium, but relatively few have been reported to contain as high percentages of calcium as citrus leaves. Not only is the ash of citrus leaves high in calcium but the total ash content is high also. It is unusual to find dried plant material that contains from 5 to 7 per cent calcium.

\section{COMPOSITION OF MOTTLED ORANGE LEAVES}

The condition of citrus trees known as mottle-leaf has been widely discussed. Much study has alreådy been devoted to it, and several hypotheses have been advanced concerning the disease. The symptoms, mode of occurrence, and general distribution were fully discussed in a paper by Briggs, Jensen, and McLane (3). The disease is commonly thought to result from some nutritional disturbance, but the cause has not been definitely determined. 


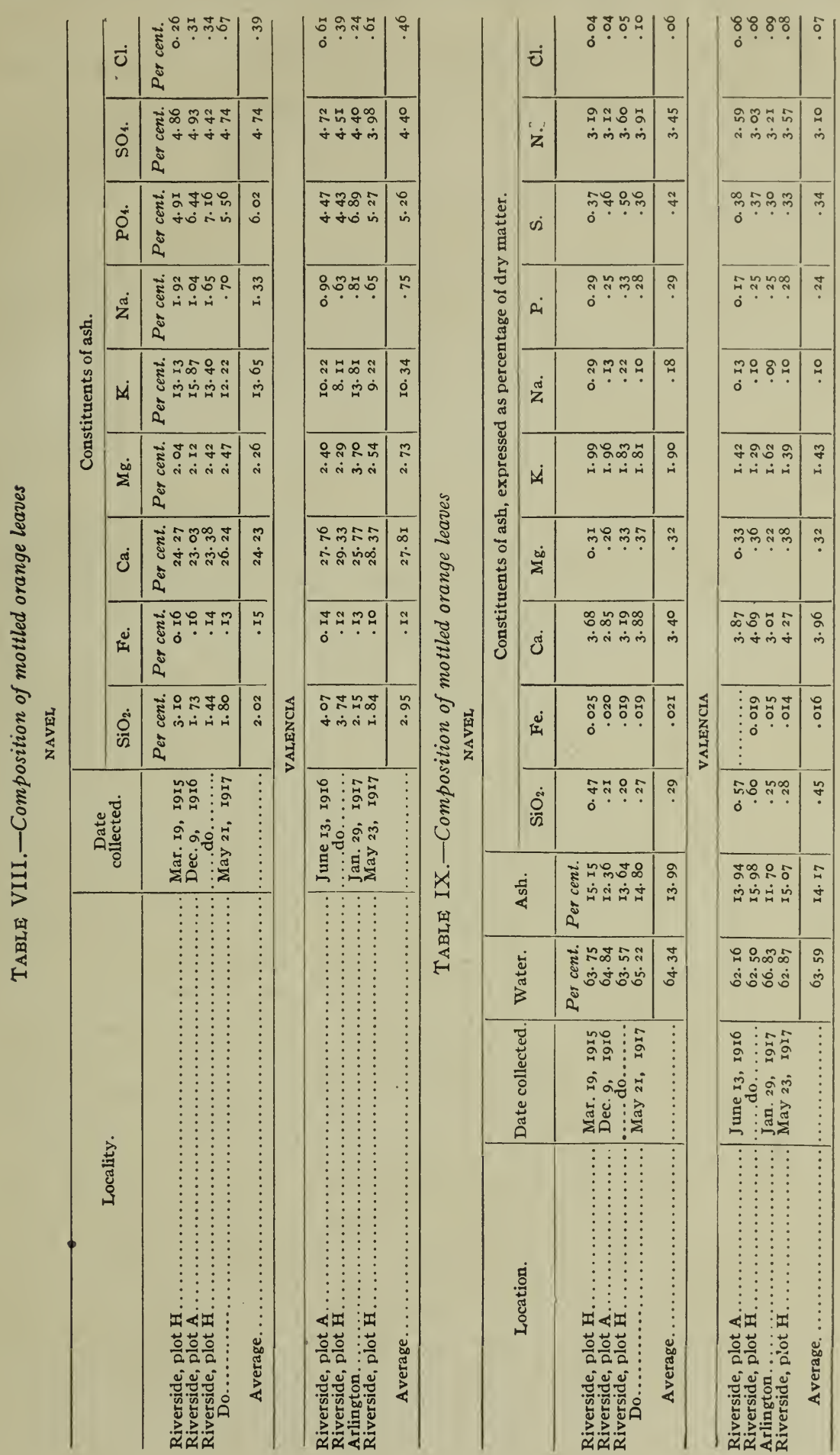


We have analyzed different portions of orange and lemon trees affected with mottle-leaf, as well as grapefruit leaves and samples representing different degrees of mottling. Most of the samples were collected from the fertilizer plots of the Citrus Experiment Station. In all cases the leaves were collected from shoots 6 or more months of age. The analysis of orange leaves in an advanced stage of mottling is presented in Tables VIII and IX.

Comparison of the data with the previously submitted analyses shows at once that the composition of mottled leaves differs considerably from that of average mature normal leaves. The principal differences are found in the greater percentages of potassium and phosphate, on the one hand, and the lesser percentages of calcium on the other. The ash of mottled leaves also contains greater percentages of magnesium and sulphate, while the iron, silica, sodium, and chlorin do not differ materially.

Considerable variations will also be noted among the different samples of mottled leaves. This is probably due to the varying degrees of mottling represented by the samples. However, every sample of mottled leaves that has been analyzed in this laboratory has been found to vary from the normal in the same general direction.

The average content of water in mottled leaves was found to be slightly higher than in normal leaves and the ash content somewhat lower. Considering the dry matter, the most pronounced differences are found in the lesser calcium content, on the one hand, and the abnormally high percentages of potassium and phosphorus in mottled leaves, on the other. The average nitrogen content of mottled leaves is also considerably above normal, as was previously pointed out by McBeth $(I I)$.

From his analyses of normal and mottled citrus leaves, Jensen (7) failed to find any consistent difference in composition. In order to insure uniformity in the age of his samples, he collected the leaves from the current season's growth. On the dates two of his samples were collected, April I 8 and May i I, the current season's growth is probably never mature at Riverside. Furthermore, the calcium content, which he reported, was very much below that of any mature normal orange leaf we have been able to find. It seems safe to conclude, therefore, that Jensen's studies were made with immature leaves. It is possible, of course, that the variations in composition incident to mottling may not occur until after the leaves have reached a certain stage of growth, although recent analysis of a sample of leaves about ro days of age, taken from severely mottled trees, indicates that the composition may begin to diverge from the normal at a very early period.

It is well known that, with the exception of severe cases of mottle-leaf, the discoloration ordinarily does not become apparent until the leaves have reached an age of 2 to 3 months. Subsequently, the degree of discoloration becomes increasingly intense until the period of normal 
maturity. In addition, mottle-leaf is usually most pronounced from September to February, when it becomes very noticeable on the leaves of the previous spring and summer cycles of growth. ${ }^{1}$

Some light may be thrown on mottle-leaf by comparing the composition of mottled leaves with that of normal leaves at different stages of growth. By reference to Tables V and VIII it will be seen that the composition of the ash of the former is quite similar to that of normal leaves approximately 6 weeks of age, although the total ash content of mottled leaves is considerably higher (compare Tables VI and IX). It is especially interesting to note that the nitrogen content of mottled leaves is somewhat higher than that of normal leaves at the age of $\mathbf{I}$ week and much greater than that of normal leaves at the age of 6 weeks.

The data indicate, therefore, that the essential nutrients are deposited in mottled orange leaves at abnormal rates. A satisfactory explanation of this fact can not now be given. The rising sap is itself probably abnormal in composition.

By calculating the weights of the several constituents contained in a unit number of mottled leaves, it is found ('Table $\mathrm{X}$ ) that notwithstanding the fact that the average size of the mottled leaves was less than one-half that of normal leaves they contained as great amounts of potassium and approximately as much phosphorus per leaf (compare Tables VII and X). On the other hand, the content of calcium was less than one-third as great as normally occurs, while the magnesium, sulphur, and nitrogen were intermediate in amount. ${ }^{2}$

The preceding analyses represent extreme cases of mottling. Samples of Valencia orange leaves at a less advanced stage have also been studied. These latter were of an intermediate size, showing the typical yellowish spots between the veins. They were selected from trees a considerable portion of whose foliage was normal and some of which bore a fair crop of fruit. The results are recorded in Table XI

The percentages of calcium and potassium closely approach those of severely mottled Valencia leaves ('Tables VIII and IX), but the phosphorus content is more nearly normal. The percentage of nitrogen was found to be no greater than occurs in normal Valencia leaves.

Thus, it appears that the early stages of mottling are first attended by the absorption of subnormal amounts of calcium ${ }^{3}$ and supernormal amounts of potassium and phosphorus, and that modifications in the absorption of nitrogen occur later.

\footnotetext{
${ }^{1}$ Mottled leaves fall off in large numbers during the latter part of the winter and early spring. New shonts developing at this season give the trees the appearance of having recovered from the disease. These latter, however, may become mottled the following fall. It is never safe to pass judgment on the state of the disease in the spring or early summer. We have never known of a leaf once severely mottled which became normal later. New leaves grown later, however, may be entirely normal.

${ }^{2}$ These data were calculated for only a portion of the samples of mottled leaves, because the average weight of the leaves was not determined for all the samples.

${ }^{3}$ Jensen $(7)$ found that the yellow spots of mottled orange leaves, similar to those discussed here, contain less calcium than the remaining portion of the leaf.
} - 


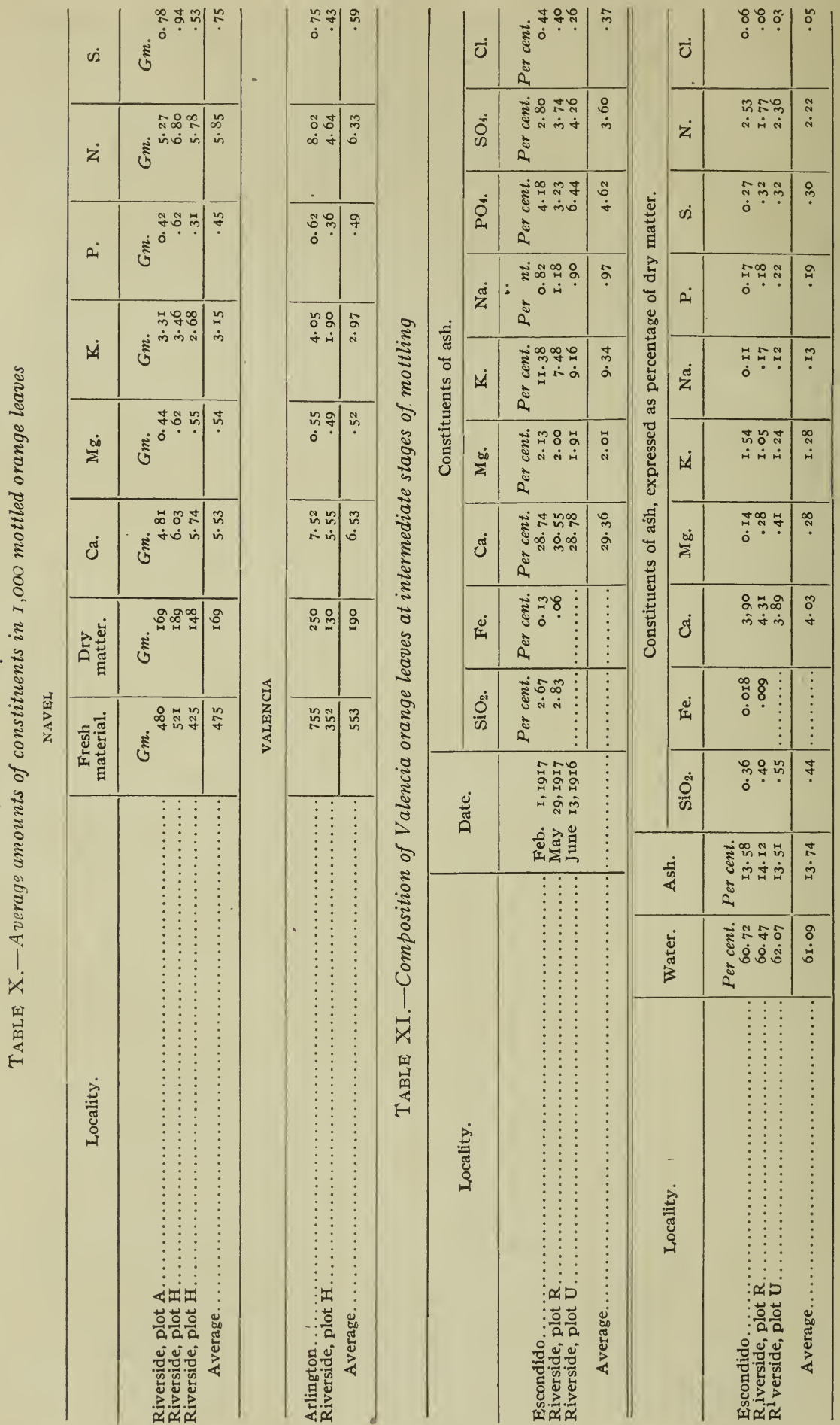


Severely mottled lemon and grapefruit leaves have also been analyzed (Tables XII and XIII).

The results show that the composition of mottled lemon and grapefruit leaves is similar to that of mottled orange leaves. As was found from the analysis of normal leaves, the composition of lemon leaves closely resembles that of Valencia orange leaves, while the composition of grapefruit leaves was found to be like that of Navel leaves. However, the different varieties and species do not vary greatly in com- position.

The fact that the composition of the leaves of one species of citrus is affected in the same general way as that of other species is not surprising, since their appearance when mottled is also similar.

As is well known, it is rare that all the leaves on a given orange tree are mottled. As a rule, those growing on the outer portions of the tree are the most severely affected, as sometimes, although not invariably, is the case with the leaves borne on the south and southeastern portion of the trees. The leaves of severely affected trees, however, may be mottled throughout the tree. Frequently the greater portion of the leaves borne by the shoots of a given growth cycle may be mottled, while those immediately preceding and following this cycle may be entirely normal in appearance. It is interesting, therefore, to compare the composition of normal and mottled leaves from the same tree.

With this end in view, samples of normal-appearing leaves were collected from the same trees from which some of the previously discussed samples of mottled leaves were drawn and on the same days. The analyses are reported in Tables XIV and XV.

The data are concordant with the previously reported analyses of normal leaves (Tables I and II). The results suggest that the leaves of different cycles of growth are mutually independent in composition and that the peculiarities in the composition of mottled leaves are not due to any special peculiarity of the tree upon which they have grown. A leaf of normal appearance borne by an orange tree the major portion of whose foliage is severely mottled, as were some of these samples, has approximately the same composition as any other normal orange leaf.

Some study has also been devoted to citrus trees affected by chlorosis ${ }^{1}$ and injured by alkali, the results of which will be presented elsewhere.

The composition of albino and etiolated plants is of interest in this connection. Church $(4,5)$ analyzed the normally green and albino portions of the maple (Acer negundo), holly (Ilex aquifolium), ivy (Hedera helix), and several other species. He found that the albino portions uniformly contained greater amounts of water than the green portions. The ash of the former contained greater amounts of potash and phosphoric acid and lesser amounts of lime than the latter, while the content of iron was approximately the same.

${ }^{1}$ Chlorosis of citrus, as it occurs in California, is distinguishable from mottle-leaf by a general fading of the chlorophyl over the entire mesophyl tissue, while mottle-leaf, as the name implies, denotes the lack of chlorophyl in spots between the veins. 


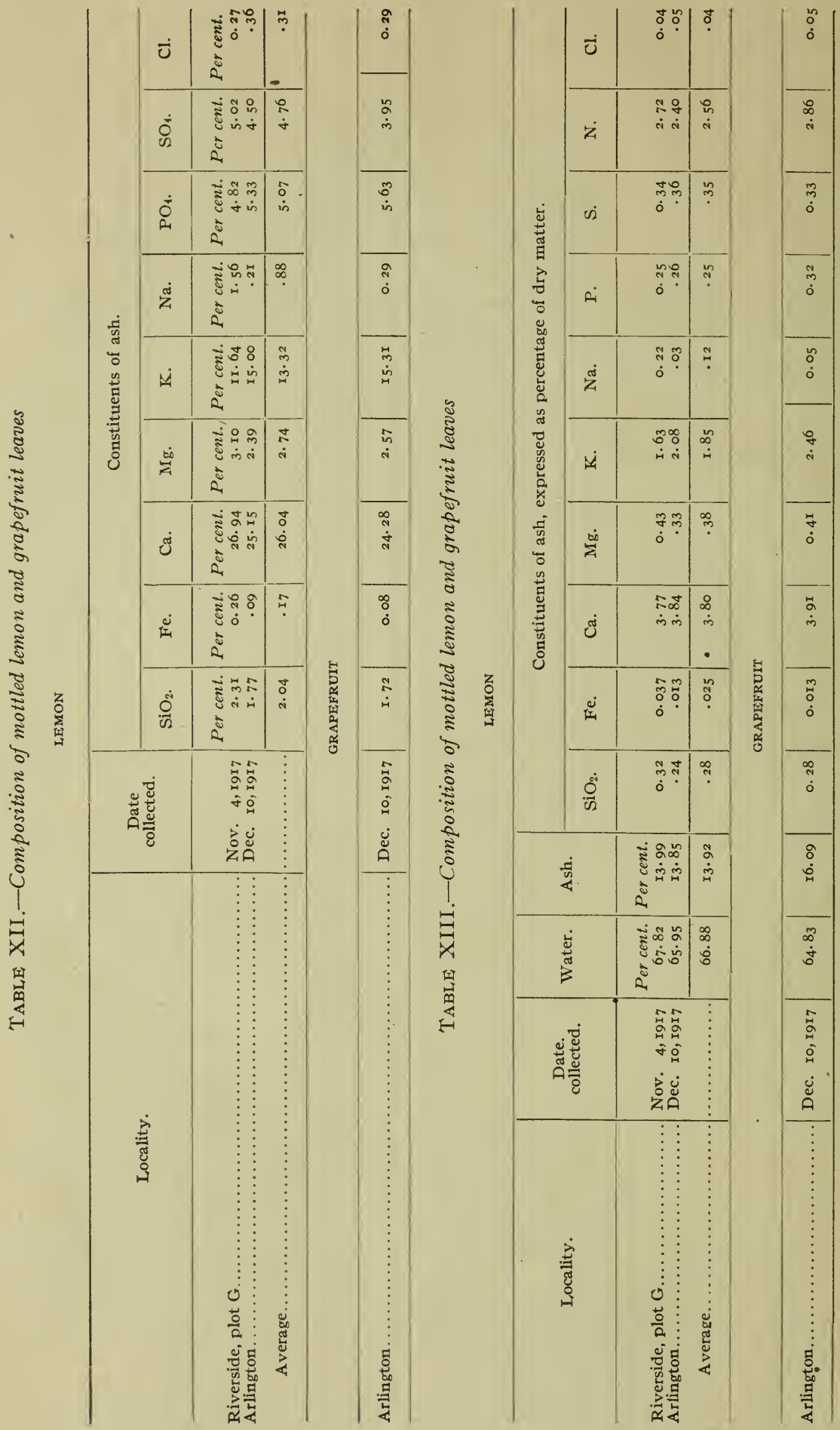




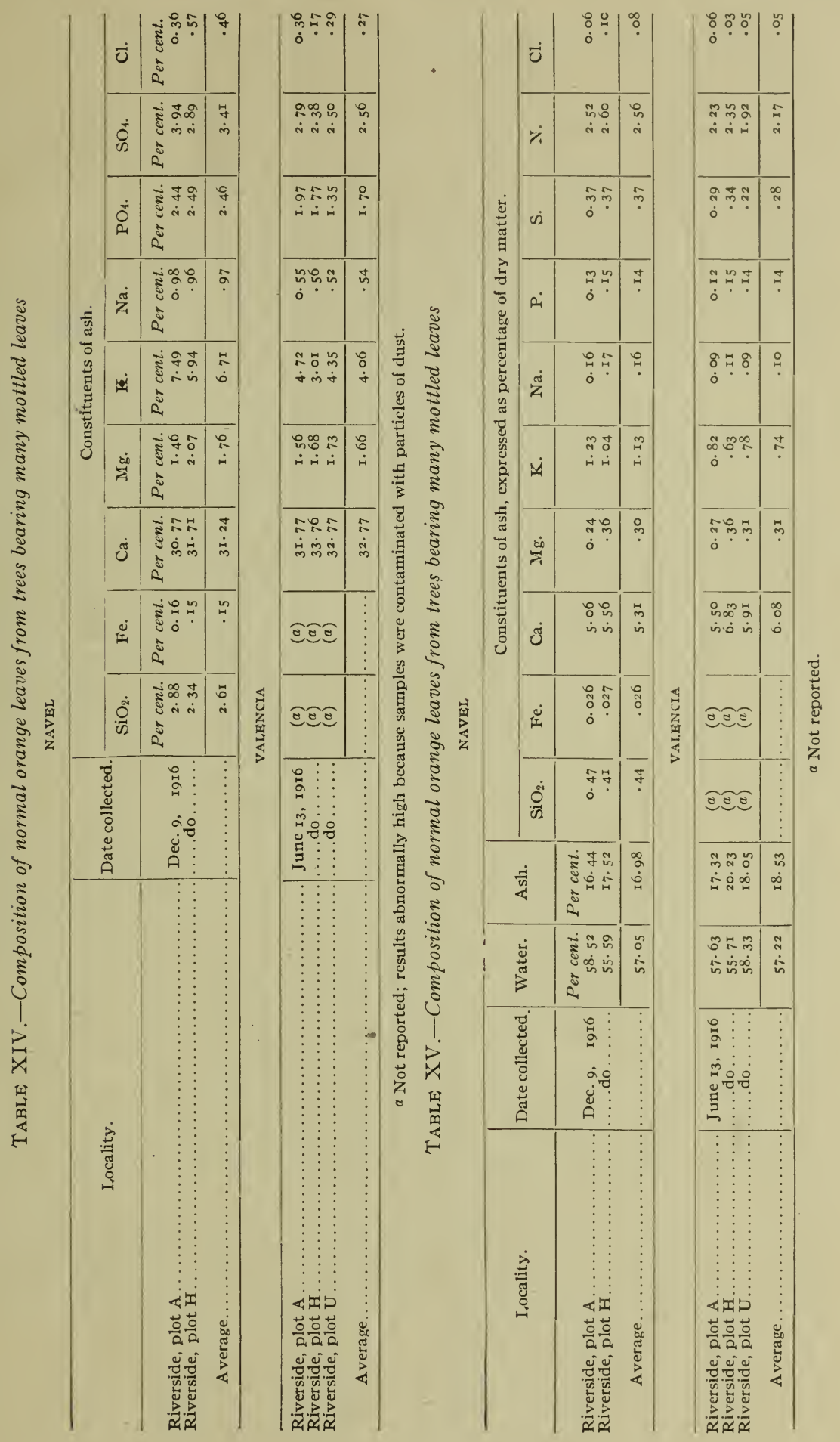


Palladin (I4) also found that the composition of the normal green and etiolated specimens of Vicia faba, the latter having been grown in the absence of light, differed in composition in the same general way as the normal and albino plants reported by Church. Weber (I6) studied the effects of different parts of the spectrum on the composition of plants and found similar effects. Jensen (7) has recorded similar observations on the leaves of the privet plant, Ligustrum aurea.

While the fundamental cause of vegetable albinism is not known, the fact that light of certain wave lengths is essential to the formation of chlorophyl is well known; but in mottled citrus leaves the deficiency of chlorophyl certainly can not be caused by an insufficiency of light.

The fact that the composition of albino and etiolated plants differs from that of normal specimens in the same general way as is the case with mottled and normal citrus leaves shows that different causes may bring about similar effects in different species of plants. This fact also suggests at once that the composition of a plant may not afford a safe basis for forming a judgment as to the cause of a particular phenomenon. A satisfactory elucidation of these questions is not possible at present owing, in part at least, to the lack of definite knowledge concerning the fundamental principles underlying the growth processes of plants. The formation of chlorophyl is undoubtedly the result of a number of interdependent factors, and it is highly probable that either the absence or the inhibition of any one of these factors may prevent the formation of chlorophyl or ultimately lead to its decomposition.

\section{COMPOSITION OF THE SAP OF ORANGE LEAVES}

Some study has also been devoted to the sap of orange leaves. The sap was obtained by first subjecting the leaves to a temperature a few degrees centigrade below zero for a period of several hours. Immediately after the leaves were removed from the freezing chamber they were quickly ground to a pulp with an ordinary meat grinder. The juice was then pressed from the pulp by the use of a hand-screw press. A portion of the juice was filtered through folded filter paper, and its specific gravity was determined by the pycnometer. Partial analysis was made on weighed portions of the juice by first evaporating to dryness and then using the methods previously described. Special investigations were also made on unfiltered portions of the sap as described below.

Mature normal leaves, collected from healthy navel orange trees on May 29, I9r8, were first studied. A sample of $86 \mathrm{Igm}$. of leaves yielded approximately $50 \mathrm{cc}$. of sap. Partial analysis gave the following results:

\begin{tabular}{|c|c|c|c|}
\hline $\begin{array}{c}\text { Specific } \\
\text { gravity. }\end{array}$ & Ca. & K. & P. \\
\cline { 1 - 2 } I. 08 & $\begin{array}{r}\text { Per cent. } \\
\text { I. } 07\end{array}$ & $\begin{array}{c}\text { Per cent. } \\
\text { 0. } 54\end{array}$ & $\begin{array}{c}\text { Per cent. } \\
\text { O. } .36\end{array}$ \\
\hline
\end{tabular}


These data show that the expressed sap of mature orange leaves is comparatively rich in solids, calcium, and potassium, but the ratio of calcium to potassium in the sap is widely different from the ratio of the total amounts of these elements in the leaf. (Table II.)

On June 5 , r918, three sets of samples of Valencia orange leaves were collected. One of these was composed of normal leaves about 6 weeks of age; another sample obtained from the same trees consisted of healthy mature leaves; whereas the third sample was chosen to represent severely mottled leaves of the previous year's growth. Each of the samples was divided into three parts, one of which was used to study the sap, another to determine the water-soluble constituents, and the third for total analysis.

The sap was pressed out after freezing as described above. The watersoluble constituents were extracted by first grinding roo gm. of the fresh leaves in a meat grinder, shaking with $\mathrm{I}, \mathrm{OoO} \mathrm{cc}$. distilled water for one hour, and filtering through filter paper. Total acidity was determined by titration with $N /$ Io sodium hydroxid, using phenolphthalein as indicator. It was necessary to dilute the sap considerably because of its dark color, and a high degree of accuracy is not claimed for the results. They are rather approximations. The acidity is expressed for convenience as anhydrous citric acid. ${ }^{1}$ The results are presented in Tables XVI, XVII, and XVIII.

TABLE XVI.-Composition of Valencia orange leaves at the age of 6 weeks

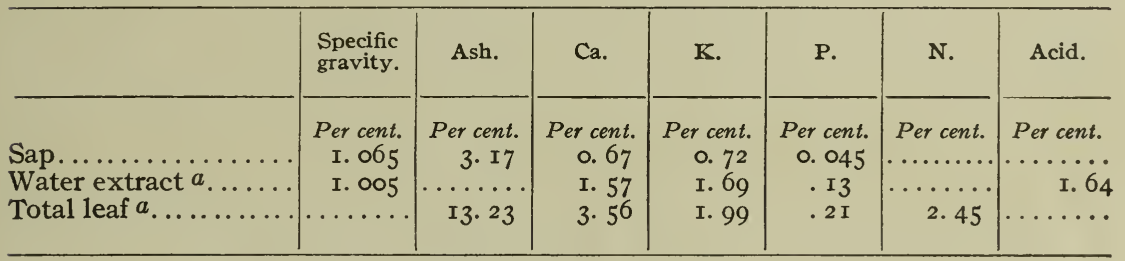

a Expressed in terms of dry matter.

TABLE XVII.-Composition of normal mature Valencia leaves

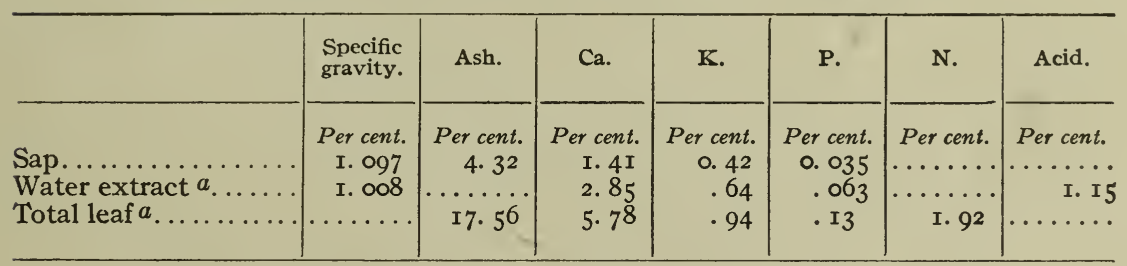

a Expressed in terms of dry matter.

1 The nature of the acid constituents of the leaves has not been investigated sufficiently to justify a definite statement as to their identity. 
The results show that the sap of Valencia orange leaves at the age of 6 weeks contains smaller amounts of dissolved solids and total ash material than mature leaves. The calcium content increases more than twofold, and the potassium and phosphorus content decreases in passing to maturity. On the other hand, the sap of mottled leaves has a higher specific gravity and a higher ash content than that of mature normal leaves. The calcium content, however, is considerably less, while the potassium and phosphorus content is much higher.

It is evident from these data, therefore, that the sap of mottled Valencia orange leaves is materially different from that of normal leaves, either when they are 6 weeks of age or mature.

The water-soluble constituents were found to diverge in the same general direction as the sap. It is interesting to note that a very high percentage of the potassium, phosphorus, and calcium of orange leaves is soluble in water.

Samples of fully mature normal leaves and of severely mottled leaves of the previous year's growth were collected from Navel orange trees of the fertilizer plots at Riverside in August, I918. The sap was expressed and used for more complete chemical study. ('Tables XIX and XX.)

TABLE XVIII.-Composition of mottled Valencia leaves

\begin{tabular}{|c|c|c|c|c|c|c|c|}
\hline & $\begin{array}{l}\text { Specific } \\
\text { gravity. }\end{array}$ & Ash. & Ca. & $\mathrm{K}$. & P. & N. & Acid. \\
\hline Sap & $\begin{array}{l}\text { Per cent. } \\
\text { I. II } 8\end{array}$ & $\begin{array}{r}\text { Per cent. } \\
4.85\end{array}$ & $\begin{array}{l}\text { Per cent. } \\
\text { I. I } 3\end{array}$ & $\begin{array}{l}\text { Per cent. } \\
\text { O. QI }\end{array}$ & $\begin{array}{l}\text { Per cent. } \\
\text { O. III }\end{array}$ & $\begin{array}{l}\text { Per cent. } \\
\text {......... }\end{array}$ & $\begin{array}{l}\text { Per cent. } \\
\text {.......... }\end{array}$ \\
\hline Water extract $a$. & I. 009 & & 2.85 & I. 64 & .180 & & 2. 75 \\
\hline Total leaf $a \ldots$.... & & I5. 06 & 4.05 & I. 98 & .243 & 3.00 & \\
\hline
\end{tabular}

a Expressed in terms of dry matter.

The results are fairly concordant with those reported above for Valencia leaves. It is again shown that the composition of the sap of mottled orange leaves differs widely from that of normal leaves. The data also show that the ash of the sap of each sample contained considerably smaller percentages of calcium and higher percentages of iron than those reported above for the ash of the leaf as a whole, while the percentages of the other constituents are not materially different from those of the entire leaf. The calcium content of the sap of Navel orange leaves appears to be lower than that of Valencia leaves. (Compare Tables XVII and XX.)

Upon studying the preceding data, it seems difficult to escape the conclusion that there must be some important physiological significance attached to the fact that the sap of mottled orange leaves contains only about one-half as much calcium and approximately twice as much potassium and nitrogen and three times as much phosphorus as normal leaves. 


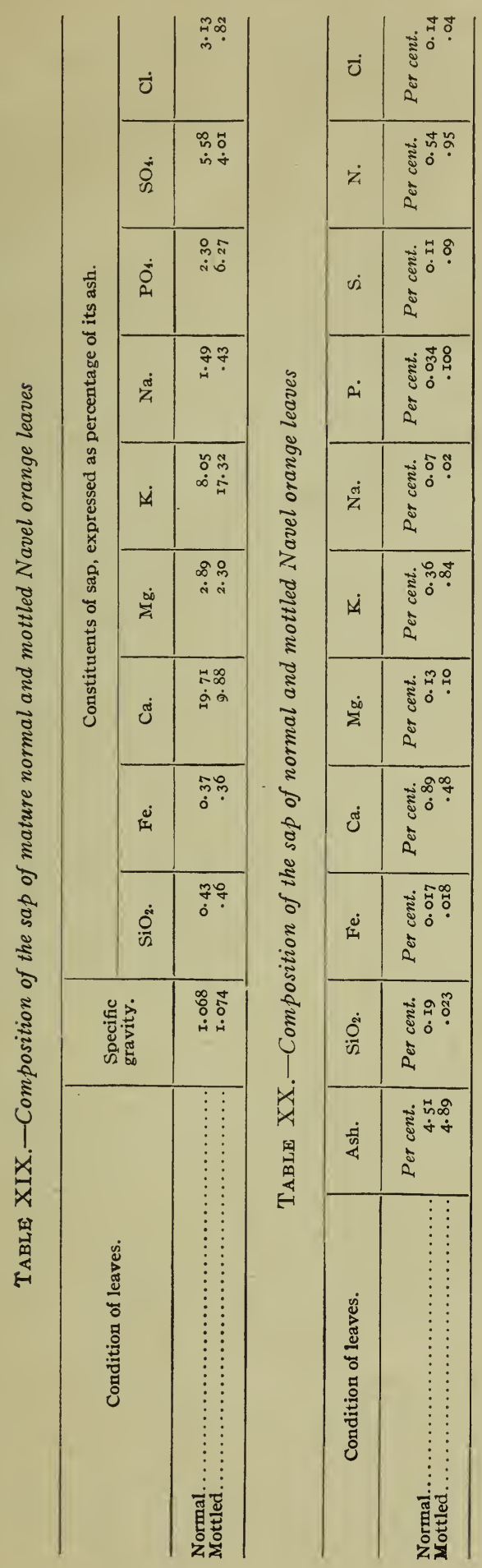


The hydrogen-ion concentration of the sap was also determined by the use of the hydrogen electrode. Mature normal-leaf sap was found to give a $\mathrm{P}_{\mathrm{H}}$ value of $5.8 \mathrm{r} 6$ and mottled-leaf sap a value of 5.647 , which implies hydrogen-ion concentrations of $0.153 \times \mathrm{IO}^{-5}$ and $0.226 \times \mathrm{IO}^{-5}$, respectively. These determinations are probably within the range of variation of different samples of the same leaves.

After the determination of the hydrogen-ion concentration, total acidity was determined by titration, using the hydrogen electrode to determine the end point. It was found that ro $\mathrm{cc}$. of the normal sap required $3 \mathrm{cc}$. $N /$ Io alkali and the mottled-leaf sap $7.05 \mathrm{cc}$. In other words, the actual acidity (hydrogen-ion concentration) of mottled-leaf sap is approximately the same as that of normal leaves. but the latter sap is more nearly saturated with base. It is probable that in each case the ionization of the acids is held at approximately the same level by the buffers present.

Samples of normal Navel orange leaves approximately one week of age, fully mature leaves, and severely mottled leaves of the previous year's growth were collected in April, r919. The sap was expressed, and the hydrogen-ion concentration and total acidity were determined by the hydrogen electrode. Freezing-point depressions were also determined in portions of the unfiltered sap. The acidity is expressed in cubic centimeters of $N /$ Io sodium hydroxid required to neutralize Io cc. of the sap.

TABI.E XXI.-Acidity and freezing-point depression of orange-leaf sap

\begin{tabular}{|c|c|c|c|c|}
\hline Condition of leaves. & Pн. & $\begin{array}{l}\text { Hydrogen-ion con- } \\
\text { centration. }\end{array}$ & $\begin{array}{l}\text { Total acid- } \\
\text { ity. }\end{array}$ & $\begin{array}{l}\text { Freezing- } \\
\text { point de- } \\
\text { pression. }\end{array}$ \\
\hline 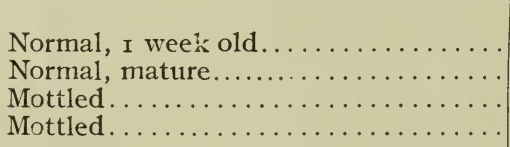 & $\begin{array}{l}\text { 6. } 069 \\
5.664 \\
5.647 \\
5.630\end{array}$ & $\begin{array}{l}0.852 \times 10^{-6} \\
.217 \times 10^{-5} \\
.226 \times 10^{-5} \\
.235 \times 10^{-5}\end{array}$ & $\begin{array}{l}\text { Cc. } \\
\text { I. } 80 \\
3.80 \\
7.00 \\
8.25\end{array}$ & $\begin{array}{l}{ }^{\circ} \mathrm{C} . \\
\text { I. } 258 \\
\text { I. } 588 \\
\text { I. } 734\end{array}$ \\
\hline
\end{tabular}

These data show that the actual acidity (hydrogen-ion concentration) of mature orange-leaf sap is approximately two and one-half times as great as that of leaves at the age of I week; but again it is shown that the acidity of mottled leaves is approximately the same as that of normal leaves. The capacity to neutralize base-that is, total acidityhowever, was fully twice as great in mature leaves as in those I week of age, while the mottled-leaf sap neutralized about twice as much base as the normal mature leaf sap.

The freezing-point depressions show that while the normal matureleaf sap is more concentrated than that of young leaves the sap of mottled leaves is more concentrated than either.

The results of the preceding investigation on the sap of orange leaves are very suggestive. They are in harmony with the preceding ash 
analyses in that they indicate that the composition changes materially as growth proceeds and that the composition of mottled leaves differs from that of normal leaves.

It is interesting to note that the total water content of mottled and normal mature leaves is roughly correlated with the concentration of the sap, but this correlation does not hold when immature leaves are compared with mature leaves.

\section{GENERAL, DISCUSSION}

It has been shown that the composition of orange leaves changes rapidly as growth takes place. The relationships between the several constituents drawn from the soil undergo important alterations. The percentages of potassium and phosphorus, when expressed on the basis of either the ash or the dry, matter, decline rapidly during the early part of the growth cycle and continue to decline, although at reduced rates, during the latter part of the growth period. The percentages of nitrogen in the dry matter also decrease as growth proceeds. The percentage of calcium, on the other hand, increases rapidly at first, and later more slowly. The concentration of iron is greatest in very young leaves, but later its concentration decreases slowly, while no very pronounced changes take place in the percentages of the other constituents. The concentration of the different constituents probably remains practically constant throughout the period of normal maturity.

As the leaves approach senility just preceding the time of normal dropping, notable amounts of potassium and nitrogen are translocated back into the stem or other portions of the tree. A part of the phosphorus also appears to leave the leaf sometime preceding the period of normal maturity. In contrast to certain cereals, the absolute content of magnesium does not decrease as maturity approaches.

It has been shown that a given orange leaf normally contains the maximum amounts of potassium, phosphorus, and nitrogen by the time it is approximately 6 weeks of age. It is interesting that the leaf also reaches its maximum size about the same time. On the other hand, the absolute content of calcium continues to increase until full maturity is reached.

Mature orange leaves are extremely rich in certain nutrients. The content of carbonated ash ranges from 14 to 18 per cent of the dry matter, and the nitrogen content is usually above 2 per cent. The most pronounced characteristic of the orange leaf, however, is found in its highly calcareous nature. When the leaf is mature, the dry matter contains from 5 to 6 per cent of calcium.

Lemon and grapefruit leaves are similar in composition to orange leaves.

The composition of mottled citrus leaves is widely different from that of normal leaves. The difference lies mainly in the smaller calcium content, on the one hand, and the greater content of potassium and 
phosphorus, on the other. Usually the nitrogen content of mottled leaves is also abnormally high. The composition of mottled orange leaves resembles that of immature leaves, although the percentages of ash and nitrogen in the former are materially greater than in the latter.

It has been shown that the absolute amounts of potassium and phosphorus contained in mottled orange leaves are fully as great as ordinarily occur in normal leaves that are two or three times as large, while the calcium content is not more than one-third that occurring in average normal leaves.

The sap of normal orange leaves becomes increasingly concentrated and acidic as growth proceeds. When mature it is especially rich in calcium and contains fully twice as much of this element as of potassium.

The abnormalities of mottled leaves noted above also occur in the sap and among the water-soluble constituents. The sap of mottled leaves contains subnormal amounts of calcium and fully twice as high concentrations of potassium and phosphorus as mature normal leaves. The hydrogen-ion concentration of mottled leaves is not materially different from that of normal leaves, but the sap is less nearly saturated with base. In other words, abnormally large amounts of unionized acids occur in mottled-leaf sap.

Limited study of portions of citrus trees other than the leaves indicates that the composition of the leaf spurs of severely mottled trees varies from the normal in much the same way as the leaves. The composition of the older wood, however, is more nearly normal. On the other hand, both the large roots and small rootlets of severely mottled trees appear to contain considerably less potassium and phosphorus than normal roots, while the calcium content is approximately normal.

Should more extended study confirm these latter observations, it would seem that the excessive proportions of potassium and phosphorus occurring in mottled leaves may have been drawn, in part at least, from the supply normally stored in the roots.

The results of these investigations suggest that mottled citrus trees are deficient in calcium, but the cause of the subnormal content of calcium can not be definitely stated.

While we recognize that growing plants have the power, through selective absorption, of regulating their composition to a marked degree, and that a given variation in the composition of a plant does not necessarily reflect a corresponding deficiency in the nutrient medium, the above data suggest that the abnormalities in the composition of different parts of mottled citrus trees may be due, in part at least, to the inability of the tree to satisfy its normal calcium requirements at critical periods.

It is well known that manure and other forms of decaying organic matter exert an ameliorating effect on mottle-leaf. It is interesting in this connection that the concentration of soluble calcium in the soil 
becomes materially increased as a result of the decomposition of such materials (8). On the other hand, the occurrence of heavily compacted layers of soil (plowsole) around the roots, especially when present immediately below the depth of cultivation, and of soils of low organic content (3) and low natural solubility afford conditions that are conducive to mottle-leaf. Where such conditions occur, it is possible that the supplies of those nutrients which are normally absorbed at relatively high rates may become inadequate. The nature and extent of the root system of citrus trees must also be considered in this connection. It is interesting that the absorbing roots of citrus trees are not provided with the usual root hairs. Consequently, they may possess less absorbing surface than is afforded by other plants that normally absorb relatively large amounts of nutrients. These and other related questions will be more fully discussed elsewhere.

The fact that mottle-leaf sometimes appears on trees that have been injured by alkali suggests the possibility that alterations in permeability occasioned by the presence of excessive concentrations of salts, or possibly toxic substances of other kinds in the soil moisture, may prevent the roots from taking up normal amounts of calcium. ${ }^{1}$

If we may judge from the composition of normal leaves, the calcium requirements during the period when mottle-leaf develops most pronouncedly are extremely heavy. The leaves at that stage normally absorb calcium at a high rate.

Just why subnormal concentrations of calcium accompanied by supernormal concentrations of potassium and phosphorus in the leaves should afford conditions that tend to limit chlorophyl production is not known, if indeed further investigations prove that such is the case. There may, of course, be no causal relationship between these facts, but rather each may be the result of causes not yet suggested.

It is recognized that calcium is not a normal constituent of chlorophyl. In addition, while iron is essential to the formation of chlorophyl yet does not enter into its final composition, we are not aware that a similar relationship exists between calcium and chlorophyl formation. Consequently, even though further study should prove that mottle-leaf can be produced as a result of an inadequate supply of available calcium, it is probable that the lack of chlorophyl and its disappearance from the localized areas of the leaves would be found to be indirect rather than direct effects of a shortage of calcium. In any event, whether the shortage of calcium or some other factor conditions the deficiency of chlorophyl, photosynthesis is doubtless reduced by the lack of chlorophyl.

With an adequate supply of nitrogen, phosphorus, and potassium present in the soil moisture, osmosis might bring about the absorption of

\footnotetext{
${ }^{1}$ As is well known, the occurrence of mottle-leaf is sometimes correlated with the species of root stock, but this phase of the subject has not been systematically investigated in California. Mr. H. Atherton Lee has called the writer's attention to his studies on this phase of mottle-leaf in the Philippine Islands.
} 
greater or lesser amounts of them, despite the deficiency of chlorophyl in the leaves; but the reasons why excessive amounts of these elements accumulate in mottled citrus leaves are not clear. It seems probable that some physico-chemical principle not elucidated by the preceding data must be fundamentally involved.

Before any explanation of mottle-leaf can be safely accepted, it is necessary to show that the disease can be produced experimentally, and that too under conditions admitting of scientific analysis. Additional studies already projected may throw further light on this subject.

Whatever may ultimately be found to be the primary cause of mottleleaf, the preceding investigations strongly suggest that the leaves are not suffering from inadequate supplies of potassium, phosphorus, or nitrogen. We have also found little, if any, indication of a deficiency of iron.

(I) Alı̃̃̃o.

\section{LITERATURE CITED}

I9OI. THE CUltivation OF ORANGES. In Jour. Roy. Hort. Soc. [London], $\nabla$. 25 , pt. $3, \mathrm{p} .34 \mathrm{I}-35^{2}$.

(2) Blair, A. W.

[I9IO.] REPORT OF CHEMist. In Fla. Agr. Exp. Sta. Rpt. [Igog]/ro, p. xxvxxxiv.

(3) Briggs, Lyman J., Jensen, C. A., and McLane, J. W.

I9I6. MOTTLE-LEAF OF CITRUS TREES IN RELATION TO SOIL CONDITIONS. In Jour. Agr. Research, v. 6, no. I9, p. 72I-740, 4 fig., pl. H, 96-97.

(4) Church, A. H.

i879. A Chemical Study of vegetable albinism. In Jour. Chem. Soc. [London], v. 35, p. 33-4I.

(5)

I886. A CHEMICAL STUDY OF VEGETABLE ALBINISM. PART III. EXPERIMENTS WITH QUERCUS RUBRA. In Jour. Chem. Soc. [London], v. 49, p. $839-843$.

(6) ENSIGN, M. R.

I9I9. VENATION AND SENESCENCE OF POLYEMBRYONIC CITRUS PLANTS. In Amer. Jour. Bot., v. 6, no. 8, p. 3II-329, 6 fig. Bibliography, p. 329.

(7) Jensen, C. A.

I9I7. COMPOSITION OF CITRUS LEAVES AT VARIOUS STAGES OF MOTTLING. In

(8) Jour. Agr. Research, v. 9, no. 6, p. I57-I66. Literature cited, p. I66.

I9I7. EFFECT OH DECOMPOSING ORGANIC MATTER ON THE SOLUBILITY OF CERTAIN INORGANIC CONSTITUENTS OF THE SOIL. In Jour. Agr. Research, v. 9 , no: 8 , p. $253^{-2} 68$.

(9) Jones, W. J., Jr., and Huston, H. A.

I9I4. COMPOSITION OF MAIZE AT VARIOUS STAGES OF ITS GROWTH. Ind. Agi ,

Exp. Sta. Bul. I75, p. 599-629, Io fig., I fold. pl. (col.).

(IO) Kelley, W. P., and Thompson, Alice R.

I9Io. A STUdy of THE Composition of THE RiCE PLANT. Hawaii Agr. Exp. Sta. Bul. 2 I, 5 I p.

(II) McBeth, I. G.

I9I7. RELATION OF THE TRANSFORMATION AND DISTRIBUTION OF SOIL NITROGEN TO THE NUTRITION OF CITRUS PLANTS. In Jour. Agr. Research, v. 9 , no. 7 , p. $183^{-2} 5^{2}$, I9 fig. Literature cited, p. $25^{1-2} 5^{2}$. 
(I2) MULLER, John.

1909. yellowing of Citrus trees. In Agr. Jour. Cape Good Hope, v. 34, no. 2, p. $149-157,2$ fig.

(I3) OliviERI, V., and GUERRIERI, F.

I895. Ricerche SUr-Li AGRUmi. In Staz. Sper. Agr. Ital., v. 28, fasc. 5, p. 287-301.

(I4) Palladin, W.

I892. Aschengehalt DER ETIOLIRTEN BlätTER. In Ber. Deut. Bot. Gesell., Bd. Io, p. I79-183.

(I5) Rowney, Thomas H., and How, Henry.

I848. ANALYSIS OF THE ASHES OF THE ORANGE-TREE (CITRUS AURANTIUM). In Mem. and Proc. Chem. Soc. London, v. 3 (1845/48), p. 370-377.

(I6) WEBER, Rudolf.

I875. UEBER DEN EINFLUSS FARBIGEN LICHTES AUF DIE ASSIMILATION UND DIE DAMIT ZUSAMMENHÄNGENDE VERMEHRUNG DER ASCHENBESTANDTHEILE IN ERBSEN-KEIMLINGEN. In Landw. Vers. Stat., Bd. I8, p. $18-48$. 



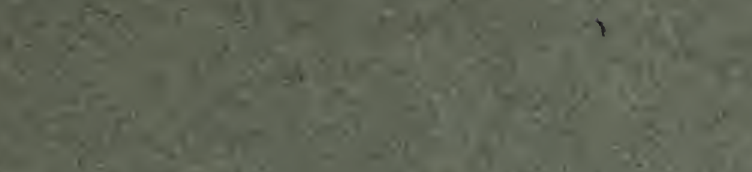

\section{(n)

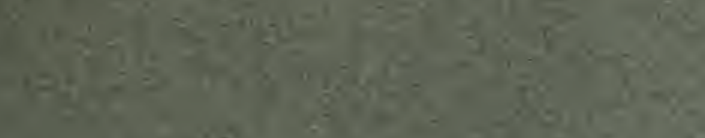

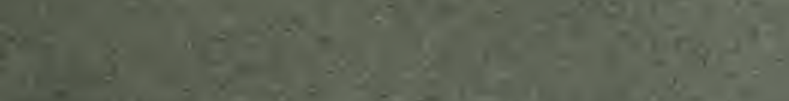

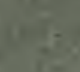

사. 24. $\sin 30=0$ $x^{2}+2$ G: in

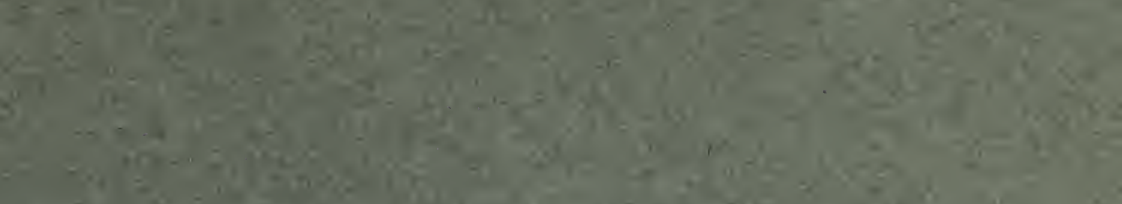
tor

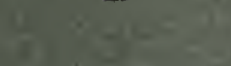

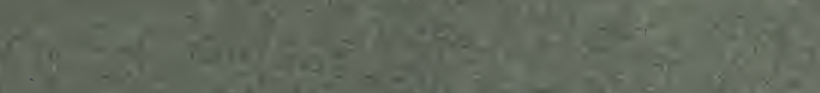

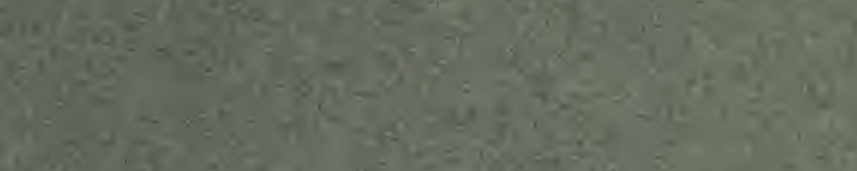

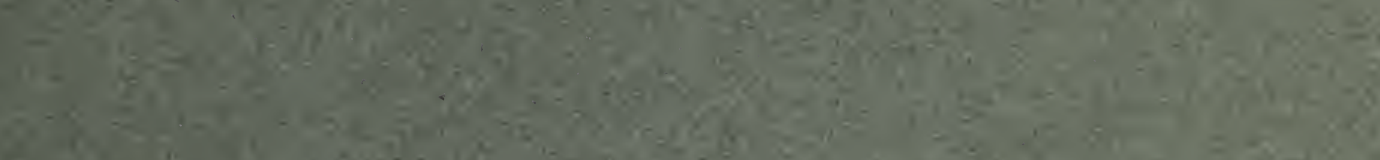

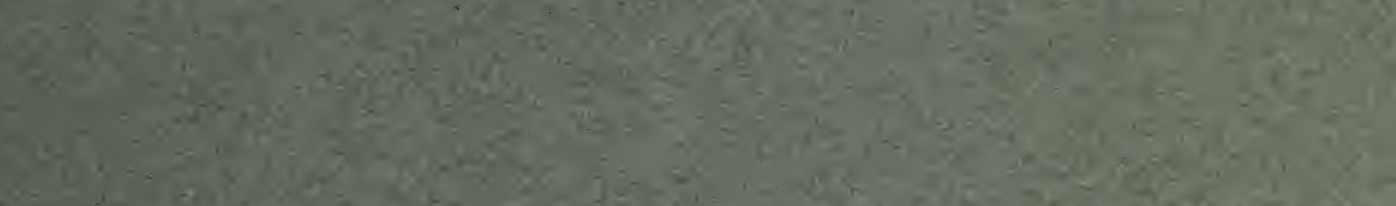

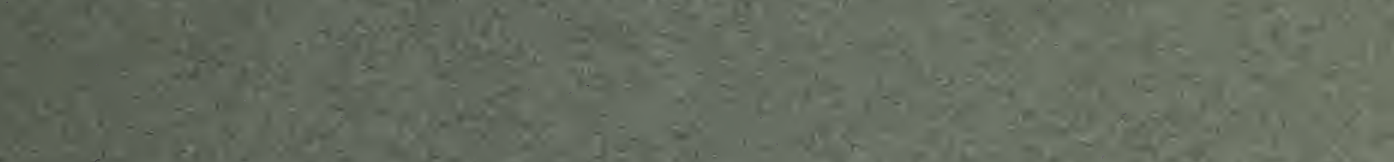

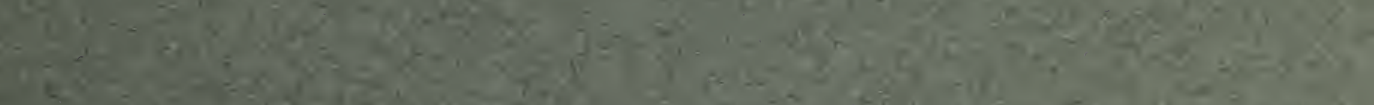

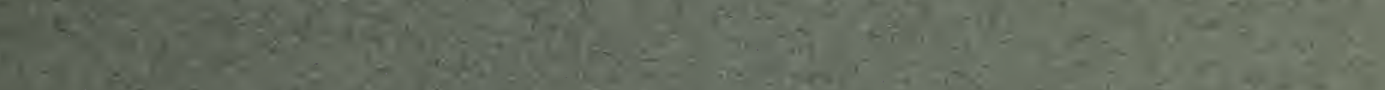

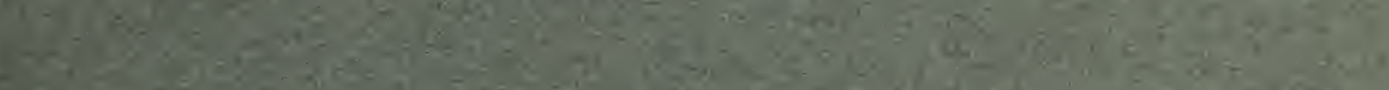

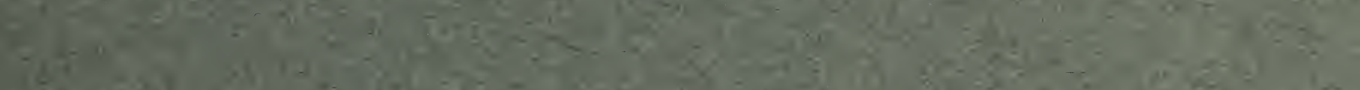

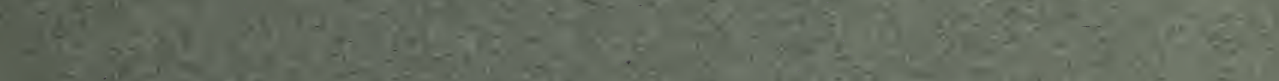

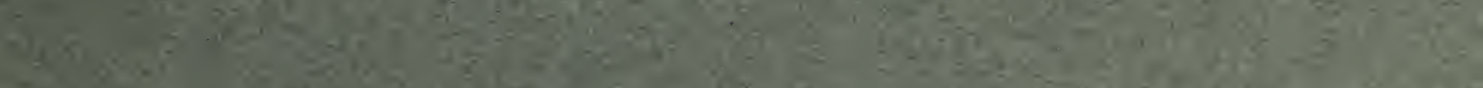

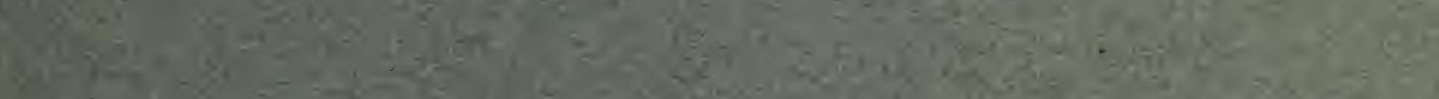

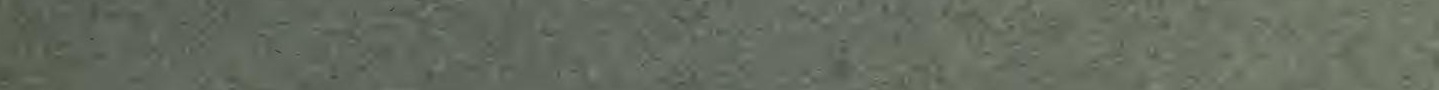

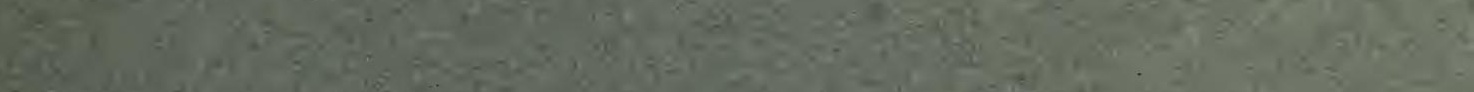

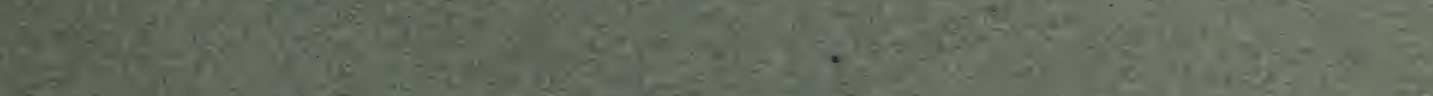

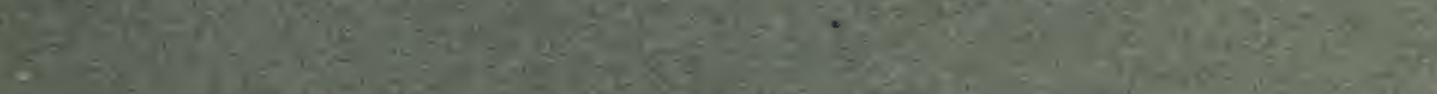

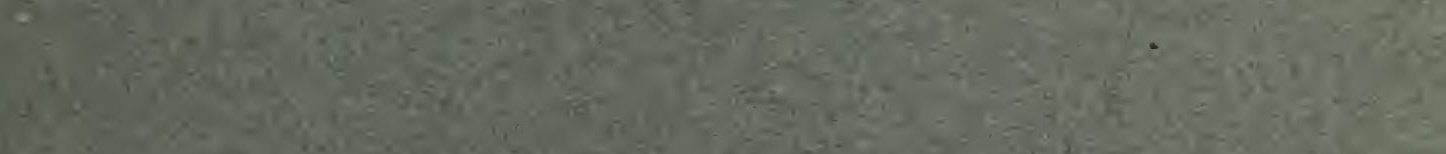

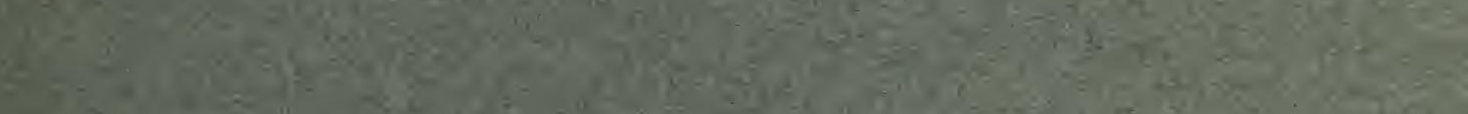

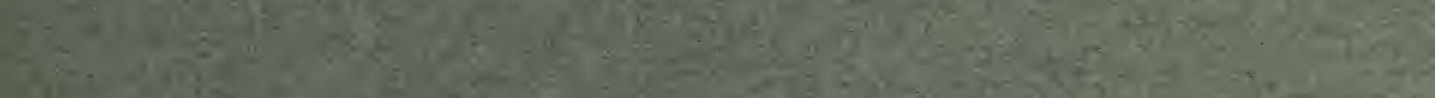

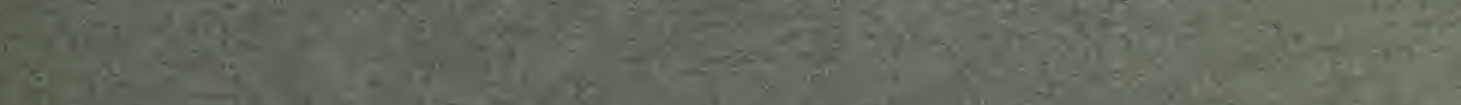

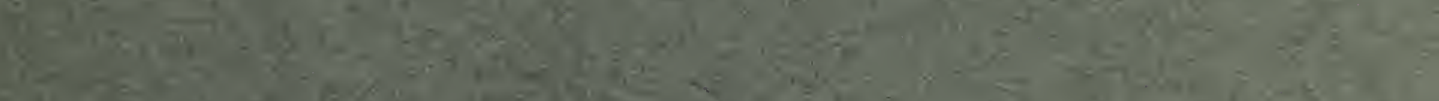

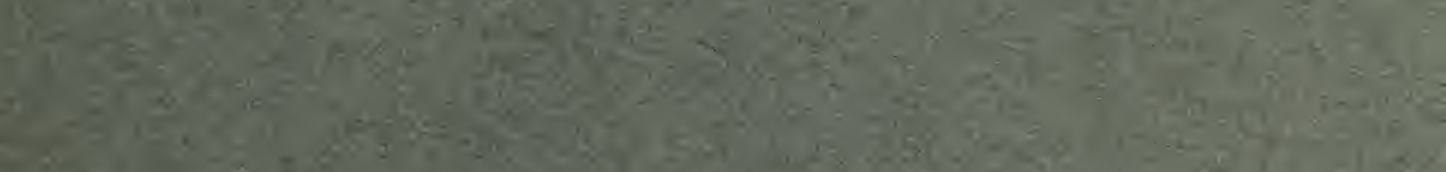

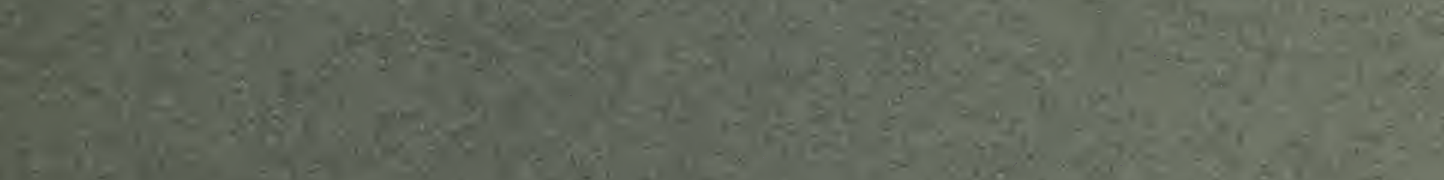

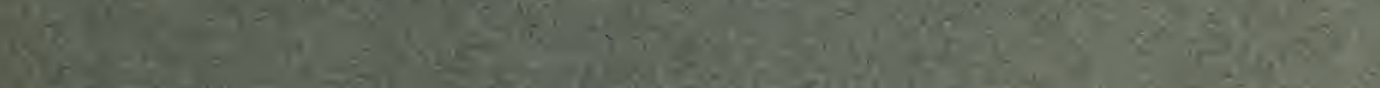


